\title{
Serous endometrial intraepithelial carcinoma: a case series and literature review
}

\author{
This article was published in the following Dove Press journal: \\ Cancer Management and Research \\ 15 June 2013 \\ Number of times this article has been viewed
}

\author{
P Pathiraja \\ S Dhar \\ K Haldar \\ Oxford University Hospital, \\ Oxford, UK
}

Correspondence: PNJ Pathiraja Oxford University Hospital, Headington, Oxford, OX3 7LJ, UK

Tel +44079 6I80 8757,

+4401865235362

Email ppathiraja@nhs.net
Background: Minimal uterine serous cancer (MUSC) or serous endometrial intraepithelial carcinoma (EIC) has been described by many different names since 1998. There have been very few cases reported in literature since EIC/MUSC was recognized as a separate entity. The World Health Organization (WHO) Classification favors the term serous EIC. Although serous EIC is confined to the uterine endometrium at initial histology diagnosis, a significant number of patients could have distal metastasis at diagnosis, without symptoms. Serous EIC is considered as being the precursor of uterine serous cancer (USC), but pure serous EIC also has an aggressive behavior similar to USC. It is therefore prudent to have an accurate diagnosis and appropriate surgical staging. There are very few published articles in literature that discuss the pure form of serous EIC. The aim of this series is to share our experience and review evidence for optimum management of serous EIC.

Patients and methods: We report a series of five women treated in our institute in the last 3 years. We reviewed the relevant literature on serous EIC and various management strategies, to recommend best clinical practice.

Conclusion: Pure serous EIC is a difficult histopathological diagnosis, which requires ancillary immunohistochemical staining. It can have an aggressive clinical behavior with early recurrence and poor survival. Optimum surgical staging, with appropriate adjuvant treatment, should be discussed when treating these patients.

Keywords: serous EIC, minimal uterine serous cancer, papillary serous endometrial cancer

\section{Introduction}

Endometrial cancer is the commonest gynecological cancer in the developed world. Over the years, most accepted structural, immunohistological, and molecular correlations have been linked with epidemiological and outcome data to arrive at a histological model of endometrial cancer. ${ }^{1,2}$ Most endometrial cancers are early stage, low grade, and of endometrioid histology (type I), with a 5-year survival of greater than $85 \% .^{4}$ Uterine serous cancer (USC) ${ }^{3}$ and serous endometrial intraepithelial carcinoma (EIC) (also known as minimal uterine serous cancer [MUSC]) comprise a highly aggressive histologic type of endometrial cancer (type II). Although type II cancer represents less than $10 \%$ of all endometrial cancers, it accounts for more than $50 \%$ of relapses and deaths attributed to endometrial carcinoma. ${ }^{5-7}$ Type II cancer is common in older patients, is associated with an atrophic endometrium, and is frequently associated with the tumor protein (p)53 gene mutation. The presence of a p53 mutation helps in the immunohistochemical diagnosis of USC/serous EIC. Serous EIC is found in the background of USC, and hence is considered a precursor of USC. ${ }^{8,9}$ Recent stud- 
ies show that serous EIC is not only the likely precursor of USC but in its pure form, demonstrates a stage-dependent potential for aggressive behavior similar to that of USC. ${ }^{10,11}$ Thus, pure serous EIC appears to be a form of minimal USC and has extrauterine disease at presentation in $33 \%$ to $45 \%$ of cases. ${ }^{10,11}$

However, pathological and clinical studies of serous EIC are limited to a few reports. Additional information is necessary to expand our knowledge in this area. This case series is an effort to correlate pathological staging with clinical outcome and propose management guidance for pure serous EIC.

\section{Patients and methods}

We identified cases of pure EIC and USC treated in our institute between 2009 and 2012, from the surgical and histopathology database. Only cases with pure EIC were included in the series, based on final histopathology. The cases excluded were comprised of all other types of endometrial cancer, including papillary serous cancer and any stage other than stage 1A serous EIC. A total of five cases of pure serous EIC were identified for analysis. Surgical and histopathology reports were reviewed using the Oxford University Hospital database (case notes) and patient records.

\section{Histopathology review}

The pathology reports and all hematoxylin and eosin (HE) slides from endometrial curetting/aspiration biopsy, subsequent hysterectomy specimen, and staging material were reviewed. Available results of peritoneal fluid cytology, pelvic nodes, omental biopsy, and uterine histology were noted.

\section{Literature review}

This paper also reviews the English language literature for studies on serous EIC/MUSC. A MEDLINE (PubMed) search of the relevant literature published in the English language over the 30-year period between January 1980 and February 2013 was performed. All publications with the keywords "uterine cancer" or "endometrial cancer" were combined and then searched for the keywords "serous endometrial cancer," "serous intraepithelial cancer," "minimal serous endometrial cancer," and "minimal uterine serous cancer." Additional publications were identified via crossreferencing from reference lists within publications retrieved from the MEDLINE search. As this malignancy is extremely rare and there is paucity of published data, all peer-reviewed case series and reviews and related case reports with adequate number of patients were included in the review. Any study that did not address the "serous" histologic types of endometrial cancer was excluded. Only the papers with pure serous EIC were considered in this review.

\section{Follow up}

Follow-up information (range 3-28 months) was obtained through the Oxford University Trust case notes and for cases referred from outside institutions, by contacting the referring clinicians.

\section{Results}

The average age at diagnosis in our group of patients was 72 years (range 64-79 years). The details of the patient/ tumor characteristics are summarized in Table 1. Five patients $(n=5)$ were identified as having pure serous EIC. All patients were managed in the Oxford Gynaecology Cancer Centre.

All the patients in the selected group presented with postmenopausal bleeding, and the initial investigations included pelvic ultrasound scans and endometrial biopsy in all five. Three patients (Patients 1, 2, and 5) also had a diagnostic hysteroscopy, during which biopsies were taken. The other two patients (Patients 3 and 4) were diagnosed by pipelle endometrial biopsy and endometrial polypectomy. Four out of five patients had the initial abnormality identified in endometrial polyps. Clinically, Patient 1 had an atrophic endometrium with an isolated polyp as well as an

Table I Patient details and histopathology data

\begin{tabular}{|c|c|c|c|c|c|c|c|c|}
\hline Age (Case no) & Presentation & Initial diagnosis & Stage & Final diagnosis & Markers & Flup & Recurrence & Living/deceased \\
\hline $64(\mathrm{I})$ & $\begin{array}{l}\text { PMB: scanty } \\
\text { bleeding }\end{array}$ & Serous EIC Polyp & Stage IA & Serous EIC & $\begin{array}{l}\text { P53, CK7, } \\
\text { CA I } 25\end{array}$ & $30 \mathrm{~m}$ & $6 \mathrm{~m}$ & Alive \\
\hline $79(2)$ & PMB & Serous EIC Polyp & Stage IA & Serous EIC & p53 & $15 \mathrm{~m}$ & $13 \mathrm{~m}$ & Deceased \\
\hline 7I (3) & $\begin{array}{l}\text { PMB: single } \\
\text { episode }\end{array}$ & $\begin{array}{l}\text { Serous adenocarcinoma } \\
\text { Polyp }\end{array}$ & Stage IA & Serous EIC & Not done & $20 \mathrm{~m}$ & Nil & Alive \\
\hline 71 (4) & PMB & Serous EIC Polyp & Stage IA & Serous EIC & Not done & $14 \mathrm{~m}$ & $12 \mathrm{~m}$ & Deceased \\
\hline $76(5)$ & PMB & Serous Ca & Stage IA & Serous EIC & $p 53$ & $4 \mathrm{~m}$ & $\mathrm{Nil}$ & Alive \\
\hline
\end{tabular}

Abbreviations: CA, carbohydrate antigen; CK, cytokeratin; EIC, endometrial intraepithelial carcinoma; p, tumor protein; PMB, postmenopausal bleeding; F/up, follow-up; $\mathrm{m}$, months. 
abnormal cervical smear with glandular cells. In Patients 2, 3 , and 5, an initial diagnosis of serous cancer was made on multiple endometrial polyps, and Patient 4 had a thickened endometrium of $6 \mathrm{~mm}$, without a polyp. None of these five patients had any obvious risk factors for endometrial cancer. One patient (Patient 5) had received hormone replacement therapy for 2 years at the age of 55. Patients 2, 3, 4, and 5 were on treatment for hypertension; Patient 3 had bowel cancer 23 years previously.

All five patients had ultrasound scan, which showed endometrial thickness varying from $4 \mathrm{~mm}$ to $8 \mathrm{~mm}$, and four out of five patients had endometrial polyps suspected. Preoperative imaging confirmed the absence of metastatic disease, and the radiological diagnosis for all five cases was stage 1A. A preoperative cancer antigen or carbohydrate antigen (CA) 125 was available in three patients, and these were within normal range. All five patients had a normal blood count and biochemistry prior to surgery.

Intraoperative findings of all five patients suggested disease confined to the uterus. The four patients who had complete surgical staging performed revealed no extrauterine disease (Table 2).

The gross appearance of the endometrial cavity showed no significant difference between the patients except for biopsy-related changes, and three out of five uterine specimens had small $(1-2 \mathrm{~cm})$ intramural fibroids.

Histopathological examination following surgery showed that Patients 1-4 had serous EIC in an endometrial polyp (Figure 1), in a background of atrophic endometrium. Patient 5 had foci of serous EIC with a polypoid endometrium and high grade nuclear atypia (Figures 2 and 3). There was no evidence of stromal invasion in any of these cases. Four patients had pelvic lymphadenectomy done, with an average node count of 19.5 (range 16 to 25), of which none were positive for disease. Three out of five cases had immunohistochemical staining for $\mathrm{p} 53$, which exhibited strong reactivity (Figure 4). Patient 1 also had CA 125 and cytokeratin (CK) 7 positivity.
The mean duration of follow up in our series was 16.6 months (range 4 to 30). Patient 1 had 30 months follow up, with distal recurrence in the right lung at 10 months from initial surgery. She was treated with a right pneumonectomy at 10 months postsurgery and presented with widespread disease at 20 months. Patient 2 died of widespread intraabdominal recurrence at 15 months postsurgery. Patient 4, died of disseminated intra-abdominal disease 14 months after surgery. Patients 3 and 5 are alive and well, 20 months and 4 months, respectively, after surgery.

\section{Discussion}

\section{Presentation}

Serous EIC (MUSC) commonly presents with postmenopausal bleeding. There are no obvious identifiable risk factors, such as nulliparity, late menopause, hormone replacement therapy, and obesity, linked to the development of serous EIC. ${ }^{12}$ According to one review, there is no link between breast and ovarian cancer syndromes and serous EIC. ${ }^{13}$ There are no proven strategies or lifestyle modifications that can reduce the overall risk of developing serous EIC. In this case series, all five patients had postmenopausal bleeding as the presenting symptom, and none of them had any breast or ovarian cancer association.

\section{Diagnosis, histology, and immunohistochemistry}

Recent studies demonstrate that serous endometrial cancer is found with a background of EIC and on its own, as pure serous EIC. ${ }^{10,11}$ Thus, pure serous EIC appears to be a form of minimal USC. The diagnosis of pure serous EIC can be difficult, particularly in biopsy specimens, as the lesion can be very focal and small, involving surface epithelium, and portions of endometrial glands. It can be easily underdiagnosed as representing metaplastic change. Although it can present in the background of serous endometrial cancer, mixed endometrioid, or sometimes with clear cell cancers, ${ }^{10,11,14,15}$ pure serous EIC is recognized histologically by markedly atypical

Table 2 Details of investigations and surgical staging

\begin{tabular}{llll}
\hline Case no & Investigations & Surgical findings & Extent of surgical staging \\
\hline I & Pelvic USS, CT scan, hysteroscopy, and biopsy & No extrauterine disease & Hysterectomy + BSO + pelvic nodes + infracolic \\
& & & omentectomy \\
2 & Pelvic USS, CT scan, hysteroscopy, and Bx & No extrauterine disease & Complete staging \\
3 & Pelvic USS, CT scan, hysteroscopy, and pipelle Bx & No extrauterine disease & Complete staging \\
4 & Pelvic USS, pipelle Bx & No extrauterine disease & Incomplete staging \\
5 & Pelvic USS, MRI, hysteroscopy, and Bx & No extrauterine disease & Complete staging \\
\hline
\end{tabular}

Abbreviations: Bx, biopsy; BSO, Bilateral salpingo-oophorectomy; CT, computerized tomography; Hyst, Hysteroscopy; MRI, magnetic resonance imaging; USS, ultrasound scan. 


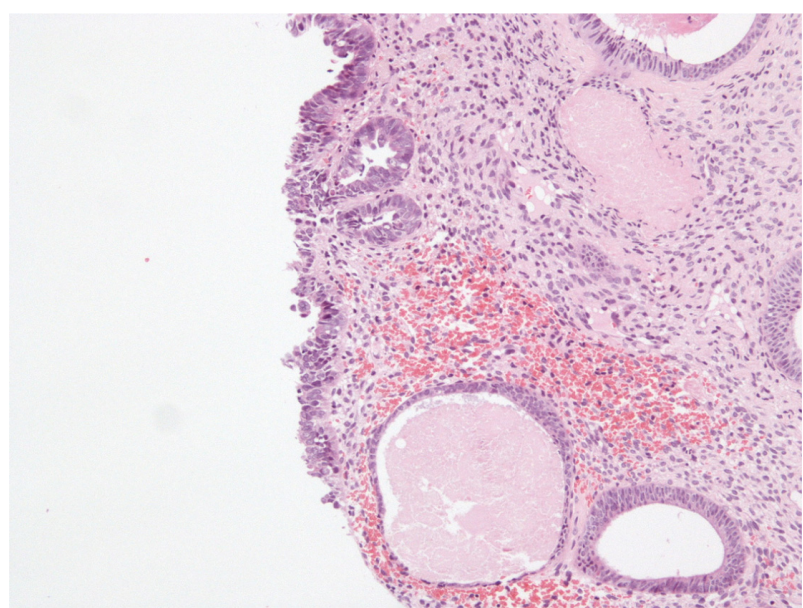

Figure I Serous EIC on endometrial polyp.

Abbreviation: EIC, endometrial intraepithelial carcinoma.

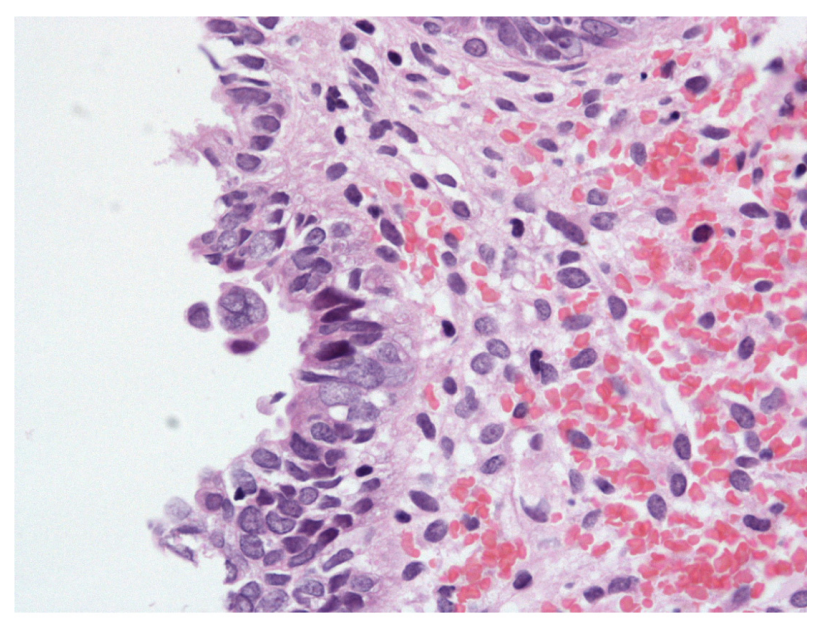

Figure 2 Endometrial polypoid surface epithelium showing serous EIC. Abbreviation: EIC, endometrial intraepithelial carcinoma.

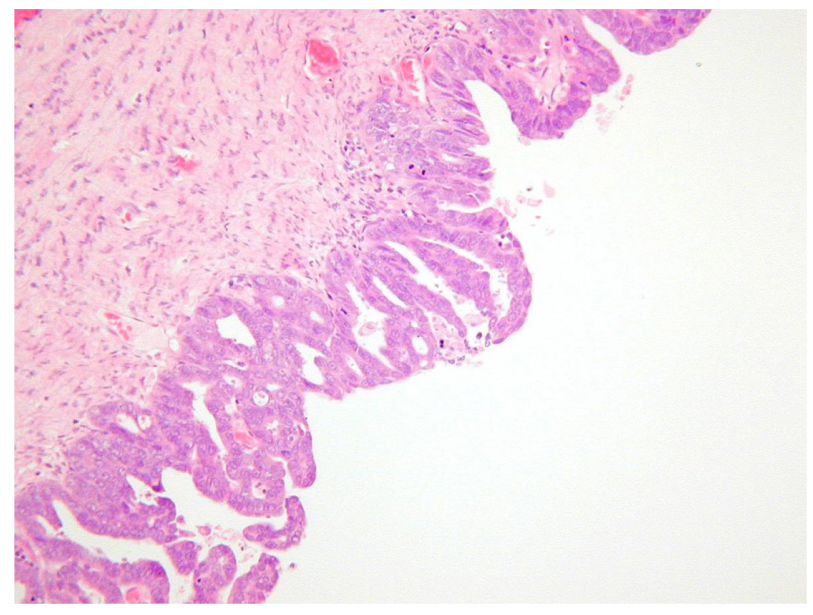

Figure 3 Serous EIC showing high grade nuclear cytology. Abbreviation: EIC, endometrial intraepithelial carcinoma.

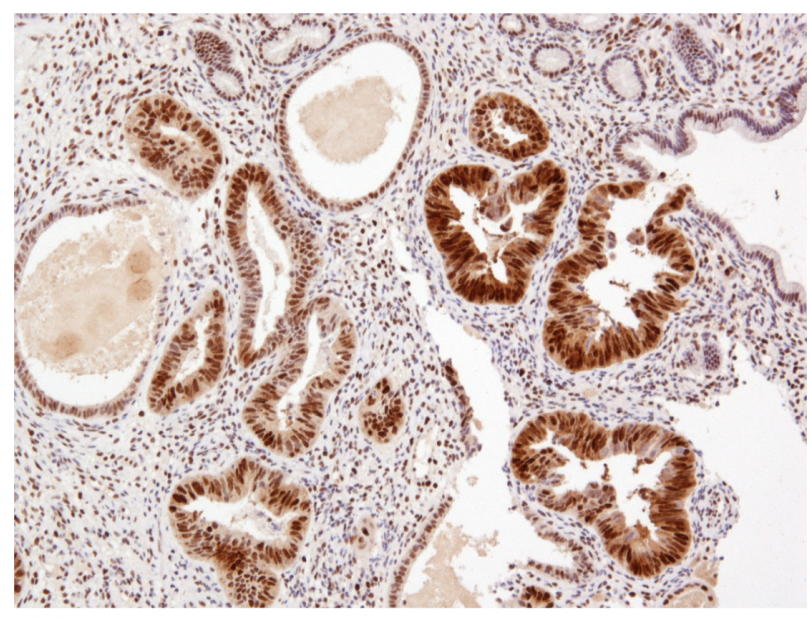

Figure 4 p53 immunostaining showing strong, diffuse positivity in serous EIC. Abbreviation: EIC, endometrial intraepithelial carcinoma.

nuclei, sometimes with prominent nucleoli, many mitotic figures, and apoptotic bodies. The cells may have a 'hobnail' appearance, and the overall architecture sometimes appears to be papillary. Various studies describe serous EIC as being confined to an endometrial polyp, ${ }^{7,11,16,17}$ which was the initial presentation in four out of five patients in this series.

Immunohistochemical stains, such as p53 and CK7, as well as estrogen receptor status have been described in literature to identify these tumors..$^{14,18}$ Three out of five specimens had p53 overexpression with negative estrogen receptor status. In contrast to endometrioid carcinomas, serous EIC/MUSC presents in an atrophic endometrium, ${ }^{8,9}$ and this was clearly demonstrated in four out of five specimens in our series.

\section{Use of diagnostic imaging}

Routine pelvic ultrasound scan is useful during the initial diagnosis, as most serous EIC presents with endometrial polyps, but staging a computed tomography (CT), scan is advisable due to its unusual behavior and presence of extrauterine disease at presentation. ${ }^{19,20}$ It is evident that at presentation, type II uterine cancer has an increased an probability of being of advanced stage compared with type I. ${ }^{9,13,19,21,22}$ Even when these tumors are of early stage at initial presentation, they can recur soon after complete surgical staging.

\section{Surgical management and adjuvant therapy}

Recent literature on early stage serous uterine/type II cancer suggests an excellent prognosis with adequate surgical staging. ${ }^{10,19,20,23,24}$ Serous EIC is considered to be the precursor of serous uterine cancer, hence, complete staging for the 
treatment of serous EIC may be recommended. All except one patient in this series had complete staging, confirmed to be stage 1A on final histopathological examination. Three out of five patients had recurrence within 12 months without adjuvant treatments. There are no specific case series or randomized trials investigating pure serous EIC, hence, it is vital to manage this early stage malignant disease aggressively with complete staging, even if the lesion is limited to a polyp.

Currently there is no consensus on the use of systemic adjuvant treatment or pelvic irradiation in early stage serous EIC, ${ }^{4,25,26}$ but with the emerging evidence of unusual sites of recurrence and aggressive tumor behavior, it may be appropriate to revisit adaptation of adjuvant treatment options, particularly since there are no proven tumor markers to detect recurrent disease. Systemic treatment with chemotherapy may also be adopted, as distant recurrent disease was one of the recognized patterns of recurrence of disease. , $^{5,21,22,24-26}$

\section{Conclusion}

Diagnosis of pure serous EIC can be challenging. Optimum surgical staging might be essential for best outcomes. Future multicenter trials, given the rarity of the entity, using adjuvant treatment in the management of pure EIC, would possibly help improve outcomes.

\section{Acknowledgments}

The authors acknowledge the Department of Histopathology, Oxford University Hospital trust for providing the histopathology slides for this publication.

\section{Disclosure}

The authors have no financial or personal relationship with any other people or organization that could have inappropriately influenced this work.

\section{References}

1. Bokhman JV. Two pathogenetic types of endometrial carcinoma. Gynecol Oncol. 1983;15(1):10-17.

2. Lax SF. Molecular genetic pathways in various types of endometrial carcinoma: from a phenotypical to a molecular-based classification. Virchows Arch. 2004;444(3):213-223.

3. Martinelli F, Schmeler KM, Johnson C, et al. Utility of colonization with frozen section for intraoperative triage prior to definitive hysterectomy. Gynecol Oncol. 2012;127(2):307-311.

4. Creutzberg CL, van Putten WL, Koper PC, et al. Surgery and postoperative radiotherapy versus surgery alone for patients with stage-1 endometrial carcinoma: multicentre randomised trial. PORTEC Study Group. Post Operative Radiation Therapy in Endometrial Carcinoma. Lancet. 2000;355(9213):1404-1411.
5. Hendrickson M, Ross J, Eifel P, Martinez A, Kempson R. Uterine papillary serous carcinoma: a highly malignant form of endometrial adenocarcinoma. Am J Surg Pathol. 1982;6(2):93-108.

6. Slomovitz BM, Burke TW, Eifel PJ, et al. Uterine papillary serous carcinoma (UPSC): a single institution review of 129 cases. Gynecol Oncol. 2003;91(3):463-469.

7. Nicklin JL, Copeland LJ. Endometrial papillary serous carcinoma: patterns of spread and treatment. Clin Obstet Gynecol. 1996;39(3): 686-695.

8. Ambros RA, Sherman ME, Zahn CM, Bitterman P, Kurman RJ. Endometrial intraepithelial carcinoma: a distinctive lesion specifically associated with tumors displaying serous differentiation. Hum Pathol. 1995;26(11):1260-1267.

9. Sherman ME, Bitterman P, Rosenshein NB, Delgado G, Kurman RJ. Uterine serous carcinoma. A morphologically diverse neoplasm with unifying clinicopathologic features. Am J Surg Pathol. 1992;16(6): 600-610.

10. Hui P, Kelly M, O’Malley DM, Tavassoli F, Schwartz PE. Mod Pathol. 2005; 18(1):75-82.

11. Wheeler DT, Bell KA, Kurman RJ, Sherman ME. Minimal uterine serous carcinoma: diagnosis and clinicopathologic correlation. Am J Surg Pathol. 2000;24(6):797-806.

12. Lackman FD, Craighead PS. Therapeutic dilemmas in the management of uterine papillary serous carcinoma. Curr Treat Options Oncol. 2003;4(2):99-104.

13. Goshen R, Chu W, Elit L, et al. Is uterine papillary serous adenocarcinoma a manifestation of the hereditary breast-ovarian cancer syndrome? Gynecol Oncol. 2000;79(3):477-481.

14. McCluggage WG, Sumathi VP, McManus DT. Uterine serous carcinoma and endometrial intraepithelial carcinoma arising in endometrial polyps: report of 5 cases, including 2 associated with tamoxifen therapy. Hum Pathol. 2003;34(9):939-943.

15. Zheng W, Khurana R, Farahmand S, Wang Y, Zhang ZF, Felix JC. p53 immunostaining as a significant adjunct diagnostic method for uterine surface carcinoma: precursor of uterine papillary serous carcinoma. $\mathrm{Am}$ J Surgl Pathol. 1998;22(12):1463-1473.

16. Silva EG, Jenkins R. Serous carcinoma in endometrial polyps. Mod Pathol. 1990;3(2):120-128.

17. Carcangiu ML, Tan LK, Chambers JT. Stage IA uterine serous carcinoma: a study of 13 cases. Am J Surg Pathol. 1997;21(12):1507-1514.

18. Kupryjanczyk J, Thor AD, Beauchamp R, Poremba C, Scully RE, Yandell DW. Ovarian, peritoneal, and endometrial serous carcinoma: clonal origin of multifocal disease. Mod Pathol. 1996;9(3):166-173.

19. Chen SS, Rumancik WM, Spiegel G. Magnetic resonance imaging in stage I endometrial carcinoma. Obstet Gynecol. 1990;75(2):274-277.

20. Rabban JT, Zaloudek CJ. Minimal uterine serous carcinoma: current concepts in diagnosis and prognosis. Pathology. 2007;39(1):125-133.

21. Sood BM, Jones J, Gupta S, et al. Patterns of failure after the multimodality treatment of uterine papillary serous carcinoma. Int J Radiat Oncol Biol Phys. 2003;57(1):208-216.

22. Baergen RN, Warren CD, Isacson C, Ellenson LH. Early uterine serous carcinoma: clonal origin of extrauterine disease. Int J Gynecol Pathol. 2001;20(3):214-219.

23. Turner BC, Knisely JP, Kacinski BM, et al. Effective treatment of stage I uterine papillary serous carcinoma with high dose-rate vaginal apex radiation (192Ir) and chemotherapy. Int J Radiat Oncol Biol Phys. 1998;40(1):77-84.

24. Soslow RA, Pirog E, Isacson C. Endometrial intraepithelial carcinoma with associated peritoneal carcinomatosis. Am J Surg Pathol. 2000;24(5):726-732.

25. Low JS, Wong EH, Tan HS, et al. Adjuvant sequential chemotherapy and radiotherapy in uterine papillary serous carcinoma. Gynecol Oncol. 2005;97(1):171-177.

26. Kelly MG, O’Malley D, Hui P, et al. Patients with uterine papillary serous cancers may benefit from adjuvant platinum-based chemoradiation. Gynecol Oncol. 2004;95(3):469-473. 


\section{Publish your work in this journal}

Cancer Management and Research is an international, peer-reviewed open access journal focusing on cancer research and the optimal use of preventative and integrated treatment interventions to achieve improved outcomes, enhanced survival and quality of life for the cancer patient. The journal welcomes original research, clinical \& epidemiological

studies, reviews \& evaluations, guidelines, expert opinion \& commentary, case reports \& extended reports. The manuscript management system is completely online and includes a very quick and fair peerreview system, which is all easy to use. Visit http://www.dovepress.com/ testimonials.php to read real quotes from published authors.

Submit your manuscript here: http://www.dovepress.com/cancer-management-and-research-journal 